\title{
Implementing the United Nations' Sustainable Development Goals for water and beyond in Australia: A proposed systems approach
}

\section{Abstract}

The 17 United Nations' Sustainable Development Goals (SDGs) form an internationally-agreed future agenda for development, and include a dedicated goal for water and sanitation (SDG 6). Yet, the presentation of the SDGs potentially invites appraisal and response 'goal-by-goal'- to the possible neglect of the mutual influences between them. We applied a systems approach to understand the interrelationships between all 17 SDGs and within SDG 6 (water and sanitation) in an Australian context. While there are multiple potential "readings" of these interrelationships, engagement in interpretation is necessary and our approach is intended to initiate debate around the commitment to the SDGs. Our reading found the SDGs for global partnerships (SDG 17) and climate action (SDG 13) are overarching and enabling influences for the other goals. Meanwhile the SDG for health (SDG 3) is influenced by all the other goals. Within SDG 6, we found that integrated water resources management (SDG 6.5) is key to achieving the other targets. Continuing inter-sectoral collaboration by government agencies will be essential to progress achievement of the SDGs. The resulting visualisation provides a tool to assist policymakers formulate the decisions necessary to achieve the SDGs.

\section{Keywords}

Sustainable Development Goals, water and sanitation, systems approach, Australia

\section{Introduction}

The United Nations' Sustainable Development Goals (SDGs) present an ambitious new framework for a sustainable future by 2030 through developing actions to achieve their targets (UN 2015). The resulting set of goals, targets and indicators lack a structure for their implementation or interaction, other than the SDG structure itself. That interaction and interdependence is a characteristic of the SDGs-but without a blueprint showing "how". Therefore, there is a need to analyse how the suite of 17 SDGs and related targets can be most effectively achieved.

One area for closer analysis relates to the linkages and points of influence between the different goals and their respective targets. Post-2015 analyses have observed that the 17 SDGs are inter-linked, through direct and indirect influences. The International Council for Science identified that four SDGs (SDGs 2-hunger, 3- health, 7-energy and 14-aquatic) were predominantly synergistic with the other SDGs; they mapped the interlinkages using a scale of interaction from 'indivisible' to 'cancelling' (ICSU 2017). Le Blanc (2015) identified that more than half of the 17 goals, or their 169 related targets, explicitly refer to at least one other goal., and over ten percent of targets link to three or more goals. Therefore, the anticipated benefits of each goal can only be achieved by a holistic approach that considers the SDGs as an interlinked set (Spangenberg 2016, Hall et al. 2016). Examples of the interlinkages and cross-influences between SDGs are numerous, such as evaluating water, sanitation and hygiene interventions (SDG 6) to reduce childhood diarrhoeal morbidity from a health and development perspective can produce a broader range of both positive and negative impacts compared to evaluation based on a health perspective alone (Loevinsohn et al. 2015). Meeting targets for the educational goal (SDG 4) can improve maternal and personal health (SDG 3), contribute to poverty alleviation (SDG 1), enhance gender quality (SDG 5) and therefore improve economic growth (SDG 8) (Nilsson, Griggs, and Visbeck 2016, Vladimirova and Le Blanc 2016).

It is important, therefore, to acknowledge that if the relationships between the SDGs and their targets are not adequately identified, framed and understood, disjointed implementation may follow with possible negative outcomes. In acknowledgement of this need, the UN recommended that the SDGs should be considered through an integrated multisectoral system approach, noting that sustainable development interventions are unable to be singly classified as economic, social or environmental (UNESCAP 2014). Taking this integrated approach can also enable the 'translation' of the multisectoral SDG framework into the operational context of sectorally-structured government agencies. The complex (but incomplete) interconnectivity between SDGs mapped out by Le Blanc (2015) provides a foundation to develop a pragmatic allocation to sectors and government agencies for effective operationalisation. However, the 'starting point' for achieving SDGs at a national or other specific level remains a challenge. 
One of the 17 UN SDGs is SDG 6, that focuses on water and sanitation (UN 2015). This goal was proposed in acknowledgement that access to clean, safely managed water and sanitation are key interventions for primary health prevention and could reduce the global disease burden by almost ten per cent (Cameron et al. 2011, PrüssÜstün et al. 2008a). The need for a specific SDG focused on water and associated sanitation and hygiene is relevant for Australia, given its proximity to south-east Asia, where one billion people lack access to drinking water that is free of contamination and sanitation facilities that separate humans from contact with their excreta, and only half of the population in Pacific Island Countries and Territories (PICTs) have access to such facilities (WHO and UNICEF 2014, 2016, WHO WPRO 2016).

Within its borders, Australia's remote Indigenous communities have been documented to have compromised health outcomes in part due to contaminated drinking water and unmaintained wastewater treatment facilities (SCRGSP 2016). The contribution of Australia to improving this situation- both within the country and within the Asia Pacificis strengthened by its membership of the UN High Level Panel on Water, consisting of 11 sitting Heads of Government and convened by the UN Secretary-General and President of the World Bank Group. This Panel is tasked with accelerating progress toward both SDG 6 and other SDGs that rely on the development and management of water resources (UN 2017). For the Australian water industry, several position papers from representative bodies have outlined the value and commitments of their sector to SDG6 in particular. The Australian Water Association has sought to 'translate' SDG 6 and related SDGs into achievable and Australia-relevant outcomes for its utility, research and government members (AWA 2017). The Water Services Association of Australia has gone further to clarify the industry's commitment to support and promote the SDGs, to work with government agencies to increase the capability and capacity to achieve SDG 6, and to achieve SDG6 within the scope of their members' operations (WSAA 2017).

This research responds to the challenge of SDG translation by seeking to achieve the objective of identifying and exploring SDG linkages and cross-influences. This is intended to promote a rich engagement with the goals, targets and indicators and thus enabling the synergies between sectors necessary to ensuring their achievement. We sought to develop a visual representation to illustrate the pattern of linkages between SDG goals and also within the targets of SDG6. We also sought to identify the value of cross-agency government attention to advise on the most effective future implementation. This was contextualised within Australia and through Australia's international obligations to enable the identification of the relevant Australian government agencies for administration. This research is intended to stimulate discussion of the interlinkages and also better clarify the priorities for funding and to identify the Australian whole-of-government approach for the attainment of the SDGs.

\subsection{Sustainable development and integrated thinking}

The 17 SDGs for achievement by 2030 represent specific issues of economy, environment, social justice, and infrastructure, with the final goal (SDG 17) focused on the partnerships and capacity to achieve these (Singh et al. 2017). The SDGs are published as a list of 17 goals, rather than in a coherent, systemic structure that displays the influences of the goals on each other (Le Blanc 2015, UN 2015). However, effective sustainable development responses require a move from siloed thinking to integrated thinking that combines multiple disciplines, and may limit the solutions identified. Commentators have stated that approaching the SDGs with a 'list-based' or 'silo' approach- albeit a natural way to proceed, given the presentation- could overlook complex interlinkages, trade-offs, synergies, positive and negative feedback loops, and not adequately prepare or understand foundational conditions prior to interventions (Griggs et al. 2013, Hall et al. 2016, Juech and Michelson 2011, Le Blanc 2015, Nilsson, Griggs, and Visbeck 2016).

Responding to the benefits of an integrated approach, the UN has stated that sustainable development interventions cannot be considered as separate economic, social and environmental aspects (UNESCAP 2014). This integrated approach can provide clearer policy guidance than the list-based approach to develop coherent and integrated policies, to direct appropriate investment and to ensure benefits (Le Blanc 2015, ICSU 2017, Watson et al. 2014). For example, for the goal for water and sanitation (SDG 6), providing sanitation in schools (SDG 6) can increase the ability for girls to remain in the schooling system post-puberty, which thus supports the attainment of the goals for education (SDG 4) and gender disparities (SDG 5) (Zhang et al. 2016). At a more specific level, target 6.2 focus on sanitation and hygiene, 'paying special attention to the needs of women and girls' - noting that funding access to safe 
drinking water can reduce the traditional role of water cartage for girls and women, and thus enable school and work participation as well as improved family health and hygiene (UN 2015, UN Women 2016).

At the time of this research (in mid-2016), the Australian Government's understanding of interlinked, synergistic SDGs was not apparent. Indeed, the official Government website on Australia's approach to the SDGs stated that the UN agenda: '...helps Australia in advocating for a strong focus on economic growth and development in the IndoPacific region ... It is also well aligned with Australia's foreign, security and trade interests especially in promoting regional stability, security and economic prosperity' (DFAT 2015). The planning towards SDG achievement is now being led by the Departments of Prime Minister and Cabinet (DPMC) and Foreign Affairs and Trade (DFAT) through an interdepartmental committee to enable a whole-of-government approach (DFAT 2018, APH 2016).

\subsection{Systems approaches for governance of the SDGs}

In contrast to the earlier Millennium Development Goals, the SDGs apply to all countries and citizens, irrespective of their level of development (UNESCAP 2014, Watson et al. 2014). This raises a potential tension between the complexity of the SDGs and the structured organisation of government agencies tasked to achieve the goals. For Australia, this domestic - as well as regional - focus requires the consideration of the development, health and environmental status of Australian and regional issues in a holistic manner (see Hall et al. (2016)). Yet the SDG presentation and scope present a challenge for policy-makers and other stakeholders to identify where, precisely, the most effective 'starting point' for achievement lies, as the interlinkages between the SDGs and their respective targets are numerous. Achieving 'policy coherence' for SDG achievement can be challenging in a governance structure, such as that in Australia, where government agencies are separated into issues-based portfolios and decision-making processes do not necessarily include tools for identifying interactions between, and feedback impacts of different policies (Nilsson, Griggs, and Visbeck 2016). A systems approach to problem-solving is one way to identify the synergistic and antagonistic dynamics between the SDGs and their contribution to multiple goals, and thus enable the critical targets to be prioritised (Le Blanc 2015, Zhang et al. 2016).

National and lower-level governance structures that have the potential to facilitate systems thinking are important, but are not necessarily well-established. At a national level, many government agencies are poorly coordinated in terms of strategies, policies and implementation of action, especially on sustainability issues. Some new organisational structures, such as 'mega-agencies' and whole-of-government mechanisms have been initiated, but this has not resulted in sustainability issues becoming an equal priority with other policy issues (Dovers and Hussey 2013). This lack of cross-agency integration on specified actions prevents full understanding, monitoring and planning of consequences across diverse applications of sustainable development (Le Blanc 2015). Indeed, the framing and understanding of the SDGs can affect which administrative portfolio has carriage of the issues - and thus how the SDG is operationalised (Dovers and Hussey 2013). For example, in Australia, responsibility for achieving and reporting on the SDGs as a whole are formally assigned only to the Department of Foreign Affairs and Trade, and the Department of the Environment and Energy (UN 2016). Instead, commentators suggest that the SDGs could best be achieved by governmental agencies working collaboratively, and potentially employing 'cross-cutting indicators' to ensure inter-sectoral coordination and engagement (Cumming, Watson, and Dangour 2016), and through integration of sustainability research with 'societal action' through a range of methods and with a variety of actors and decision makers (Fischer et al. 2007).

A water-related example of integration can be seen in sustainable approaches to urban water management, which recognise that best practice must deliver not only water security, but health and environmental outcomes amid the pressures of rapid population growth, urbanisation and climate change (Marlow et al. 2013). These approaches require coordinated involvement of numerous specialist or 'issue-based' organisations such as typical government sectors (Rogers et al. 2015). Analysis has identified that working within the (often) narrow mandate of individual specialist organisations is a barrier to achieving the coordinated and aligned action necessary to deliver long term change (Rogers et al. 2015). In addition, given that the jurisdiction of organisations rarely corresponds to geographical boundaries of freshwater resources and river basins, collaboration and coordination across regional or national boundaries will also be required (Vorosmarty et al. 2010). This integration can be seen by the Australian Government's commitment- through its prominence in the UN High Level Panel on Water- to bring together Australian expertise across agencies and sectors to manage water data, innovate drinking water provision to remote communities, and to support water and sanitation provision through aid funding in the Asia Pacific (Office of PM 
2016). Within the Australian water industry, the Water Services Association of Australia has proposed that the SDGs leverage collaboration between water utilities, governments, regulators, other stakeholders and the community to create a sustainable future (WSAA 2017).

However, previous attempts at cooperation and negotiation has been limited and weak (Gallagher et al. 2016). To build this capability, systems thinking and system-wide knowledge is required for sustainable development initiatives (Düspohl, Frank, and Döll 2012). This thinking reflects an understanding of the relationship between system structure and the dynamic behaviour of a system (Senge 1990, Senge and Sterman 1992). The conventional linear approach focuses on the events (e.g., algal blooms) and patterns (e.g. increasing nutrient concentrations), rather than considering the systemic structures that led to these- such as urban development (Maani and Cavana 2007). This is typical of a siloed approach that ignores the role of interlinkages, trade-offs and feedbacks operating within a system in influencing the dynamic system behaviour (Maani and Cavana 2007). In attempting to solve a problem, the emergence of unintended consequences associated with well-intentioned actions can worsen the situation (Sterman 2000, Senge 1990). Instead, a systems thinking approach is based on the central concept of understanding how reinforcing (positive) and balancing (negative) feedbacks can combine to link structure to the dynamic behaviour of an integrated system.

\section{Method}

The overall research objective was to identify a 'starting point' for SDG action and investment by the relevant government agencies, based on a sound understanding of the various influences of the SDGs on each other and the targets within SDG 6. A systems approach provides a whole-of-system perspective to identify synergies and antagonisms between components - such as SDGs (Zhang et al. 2016). To respond, a systems approach was adopted. This approach was considered appropriate to the research objective, as it was anticipated that a method employing a systems approach would expose the complexities through participant debates, challenging of disciplinary expertise, and reveal the need for trade-offs to reach a resolution. This aligns with the systems-based methods to expose interlinkages and initiate debate over the complexities has also been collated by the UN Economic and Social Commission (UN ESCAP 2017).

The initial step to conduct this systems approach was to gather a multidisciplinary group of researchers and encourage a sharing of their distinct disciplinary expertise while also engaging in the development of a combined method (Mitchell, Cordell, and Fam 2015). An open invitation was issued in April 2016 to over 50 academics across our university to join the research team. Eleven researchers elected to participate, representing a range of disciplines, including public health, communication, politics, systems analysis, humanitarian engineering and sociology. They include the authors of this journal article. They included a balanced spectrum of seniority: early career researchers (4), mid-career researchers (3) and professors (4). The collection of combined knowledge and, by default, incomplete knowledge, is somewhat overcome by aggregating understanding to addressing the issue as a group, and by using a systems approach (Hovmand 2014).

The researchers convened in two workshops (May 9 and 30 2016) to identify the interlinkages among the SDGs, and create directed acyclic graphs (DAGs) that clarified the cause-and-effect relationships among the goals (Nadkarni and Shenoy 2004, Cain 2001). The first workshop sought to create a visual representation of the SDG relationships. This was based on the perceived value of previous research that applied visual approaches to present these complex and dynamic systems (see (Le Blanc 2015, Karazhanova 2015, Nikolova et al. 2017, ICSU 2017). To display the influences and connections between the SDGs an acyclic systems approach was identified as an appropriate technique to provide a 'time slice' (a static network) of the dynamic SDG network (Richards 2016). This approach produces a onedirectional graphical diagram to display the cause-and-effect relationships (without feedbacks) between determinants ('parent nodes') and descendants ('child nodes') (Cain 2001).

The Bayesian Belief Network (BBN) approach was used as a methodological blueprint for developing the DAG. A BBN can be based on quantitative data and/or on qualitative knowledge (Nadkarni and Shenoy 2004, Cain 2001). For this research question, qualitative knowledge was sourced, involving expert elicitation of the structure of the DAG from our multidisciplinary team. This technique was informed by earlier research that sought such expertise (see (Henriksen and Barlebo 2008, Kuhnert, Martin, and Griffiths 2010, Nadkarni and Shenoy 2004)). The dual benefits of 
this approach are that that it integrates and elicits knowledge- especially for environmental management, while also integrating environmental and socio-economic complexity and uncertainty in a practical manner (Henriksen and Barlebo 2008, Düspohl, Frank, and Döll 2012). The four stages to the applied method were:

1. Workshop 1: During the first workshop, we divided into two random, multidisciplinary groups, and were provided with 17 cards featuring the SDGs. Each group created a diagram arranged according to the order in which one SDG was understood to directly influence other SDGs in the Australian and regional context. The activity was then repeated for the eight targets of SDG 6, again using cards to physically create the physical map.

2. Workshop 2: A second workshop involved five researchers self-selected from the initial group. It aimed to resolve the differences between the diagrams through discussion between the two sets of diagrams, to complete one final DAG for the 17 SDGs and for the eight SDG 6 targets. The final diagram was recorded by photos and transcribed into Vensim software to create a digital representation of the results (Vensim 2016).

3. Determine strength of influence: The next stage of the method was to agree on the strength of influence between the goals connected within our resulting diagram. For this exercise, we limited our methodology to a conceptual diagram to demonstrate meta-level relationships without the inclusion of conditional probability tables that are often used in BBNs. The strength of influence was decided using a form of judgment by our research team members, known as expert elicitation (Nadkarni and Shenoy 2004). We reviewed the final diagram and identified the strength of influence between each SDG in terms of minor, medium and major influences, based on our expertise and disciplinary knowledge of the relationships and the specific issues. The diagram was amended to display connecting lines, with increasing width presenting a stronger influence.

4. Identify relevant government agency: By using a simplified form of policy analysis (Wilson 2006), we individually reviewed the SDGs against our understanding of the existing Australian federal department portfolios (current as of May 2016), and identified the SDGs of most relevance to each. We then mapped the 17 SDGs to the 21 existing portfolios most likely to be assigned responsibility for implementation of each of the respective goals - both within Australia and regionally.

This methodological approach provides value on two levels. At the topic level, there is a need to look at the SDGs systemically, as mutually influencing, since there is such a temptation to reduce them to the targets and focus there. At the methodology level, the experts' workshop approach is a well-recognised methodology where other methods are less practicable.

\section{Results and Discussion}

\subsection{Achieving the 17 SDGs in Australia}

The resulting visual representation of the relationships between the SDGs is displayed in Error! Reference source not found.. The overarching influences are located towards the top of the diagram. The multiple connections (and associated strength of those connections) are represented by arrows between the SDGs of varying widths, where the wider arrows represent a major influence. The intention is that these results can provide guidance to government agencies- especially in Australia- on the 'starting point' for policy development. This would be required before any form of policy revision or SDG achievement.

The goals for global partnerships (SDG 17) and climate action (SDG 13) were recognised as major and overarching influences, and were thus positioned at the top of the diagram. These were considered as 'enabling' goals that generally influenced all of the other goals through a range of complex links. The SDG for partnerships (SDG 17) was also considered to influence the priorities of international aid and national spending - thus facilitating the attainment of the other SDGs overseas.

The goals regarding poverty alleviation (SDG 1), work and economy (SDG 8) and education (SDG 4) were all identified as major 'parent' influences on the other goals and were considered the foundational conditions on which all further action would be built. In turn, poverty alleviation (SDG 1) and work and economy (SDG 8) were both found to have major influences on peace and justice (SDG 16). Education (SDG 4) was identified as a major influence on improving 
the capacity for equality (SDG 5) in Australia, and a medium influence on increased clean energy (SDG 7) through research, training and uptake.

The goal for water, sanitation and hygiene (SDG 6) was identified as being influenced by, and influencing other, goals - to become both the descendant and determinant of other SDGs. We considered SDG 6 to be directly determined by gender equality (SDG 5) that can affect participation of women and minority groups involved in management of drinking water and sanitation. The SDG for health and wellbeing (SDG 3) was identified as a descendant of water and sanitation (SDG 6), given the influence of safe and accessible water for drinking and sanitation on physical health (Prüss-Üstün et al. 2008b). 'Life below water' (SDG 14) was also considered to be a descendant of water and sanitation (SDG 6), as quality of water inflows can influence health of aquatic and marine ecosystems- that can then influence food security and hunger (SDG 2).

After much debate during the second and final workshop, the goal for health and wellbeing (SDG 3) was identified as being influenced by all the other SDGs. This reflects the interdependency of health and wellbeing outcomes with the range of physical and social aspects including, most directly, with clean water, adequate sanitation and reduction of hunger and malnutrition (WHO 2014b, a).

Of note, it is likely that other relationships may be identified by other participants with different disciplinary and experiential background. For example, the protection of forest ecosystems and biodiversity (SDG15) could be argued to significantly influence water quality and availability (SDG6). The full range of possible alternative relationships and interlinkages are note possible to identify within the practical time and knowledge available. Instead, the results are intended to initiate discussion and debate regarding the value of the interlinkages.

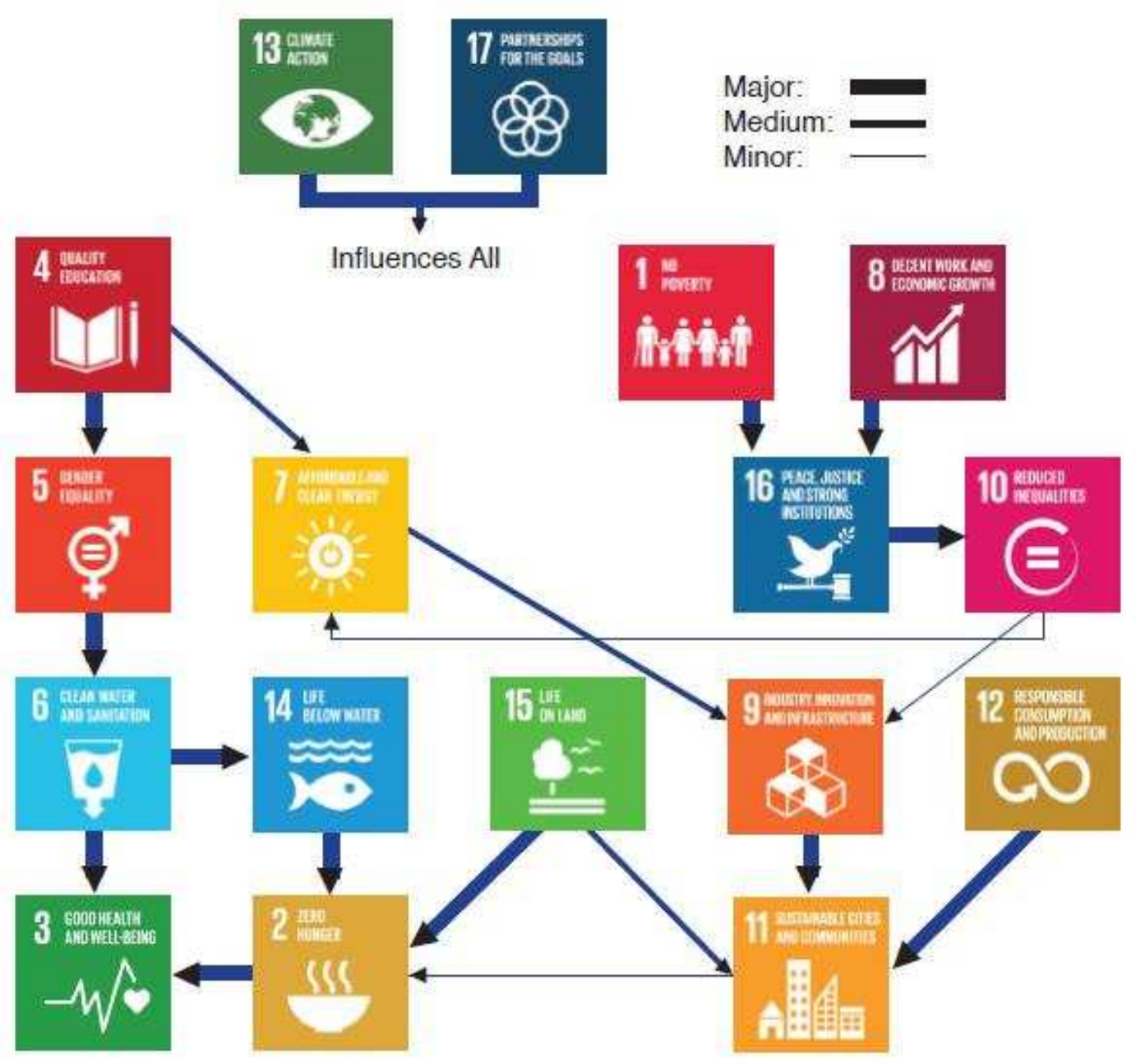

Figure 1: Interlinkages and strength of influences (as indicated by line thickness) between all 17 UN Sustainable Development Goals (Source: Authors) 
The management of the SDGs within relevant Federal Australian government agencies is displayed in Figure 2, using the agency names and structures that were current at the time of research in mid-2016. The diversity of the SDGs and their respective targets created difficulties in assigning each SDG to one or more responsible agency. We found that most SDGs could be aligned with an average of three agencies; the SDGs for peace and justice (SDG 16) and global partnerships (SDG 17) had greatest relevance to the most agencies, with alignment to ten and eight agencies respectively. This reflected the interlinkages and overlaps of these more 'enabling' SDGs. Several SDGs were difficult to assign clearly to an agency, such as SDG 10 (reduced inequalities), SDG 12 (responsible consumption and production), and SDG 13 (climate action). Furthermore, no single agency was considered to have clear responsibility for the entire set of 17 SDGs. This contrasts with the UN's identification in mid-2016 of SDG assignment predominantly to the Department of Foreign Affairs and Trade, and to the Department of Environment and Energy (UN 2016). It is noted, however, that these two agencies were relevant to the largest number of goals among the 21 agencies (seven and six goals respectively).

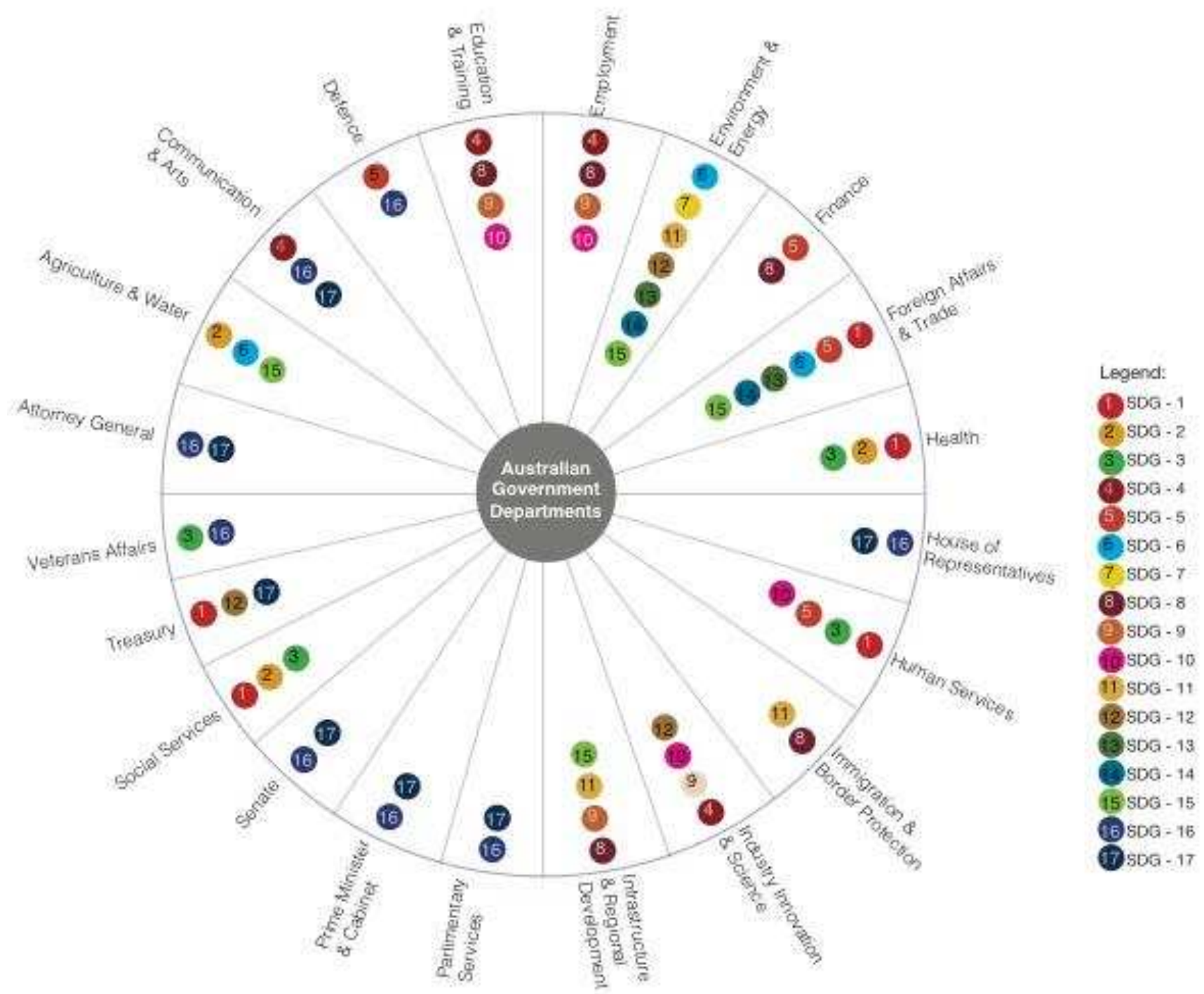

Figure 2: Proposed integrated alignment of SDGs with Australian Federal Government portfolios (as at mid-2016) (Source: Authors)

It is important to note that, since conducting the workshops and analysis in mid-2016, structural and name changes have occurred to some of the Government Departments (Australian Govt 2018). Furthermore, a more nuanced understanding of the SDGs by Government agencies has become apparent since the earlier website statement regarding Australian action on SDGs as focused on 'economic growth and development in the Indo-Pacific region' (DFAT 2015). The planning towards SDG achievement is now being led by the Departments of Prime Minister and Cabinet (DPMC) and Foreign Affairs and Trade (DFAT) (DFAT 2018). In late 2016, DPMC established an interdepartmental committee to enable a whole-of-government approach to achieving the SDGs, to avoid the siloed approach from each SDG being allocated to a specific agency (Department) for achievement (DFAT 2018, APH 2016). These changes have been accelerated since Australia made a commitment to the UN to deliver their Voluntary 
National Report in mid-2018 (DFAT 2018). In parallel, the Senate Standing Committee on Foreign Affairs, Defence and Trade launched a parliamentary inquiry in late 2017 to consider Australia's domestic and international efforts on the goals (APH 2017). The Australian Bureau of Statistics has been tasked to gather data to report on progress against the SDG indicators (ABS 2018).

\subsection{Achieving SDG 6 targets on water, sanitation and hygiene in Australia}

The visual representation of the relationships between the targets of SDG 6 is displayed in Figure 3. It placed capacity-building and cooperation (SDG 6a) and local community participation (SDG 6b) outside the remaining targets as they are concerned the achievement of SDG 6, while the other targets were closely focused on the delivery of outcomes (see Bartram (2015)). It features the target of integrated water resource management (SDG 6.5; IWRM) as the key influence of the other targets- with a major influence on water efficiency (SDG 6.4) and the health of water-related ecosystems (SDG 6.6). These targets in turn are strong influences of water quality (SDG 6.3) and also influence sanitation and hygiene (SDG 6.2). Water quality (SDG 6.3) was considered to be a major influence on drinking water (SDG 6.1), with some influence also from sanitation and hygiene (SDG 6.2). The group resolved that the main resulting goal of SDG 6 was safe, accessible and affordable drinking water (SDG 6.1), as this enables health and wellbeing (SDG 3), which is the main intended outcome of all 17 SDGs, according to the SDG DAG.

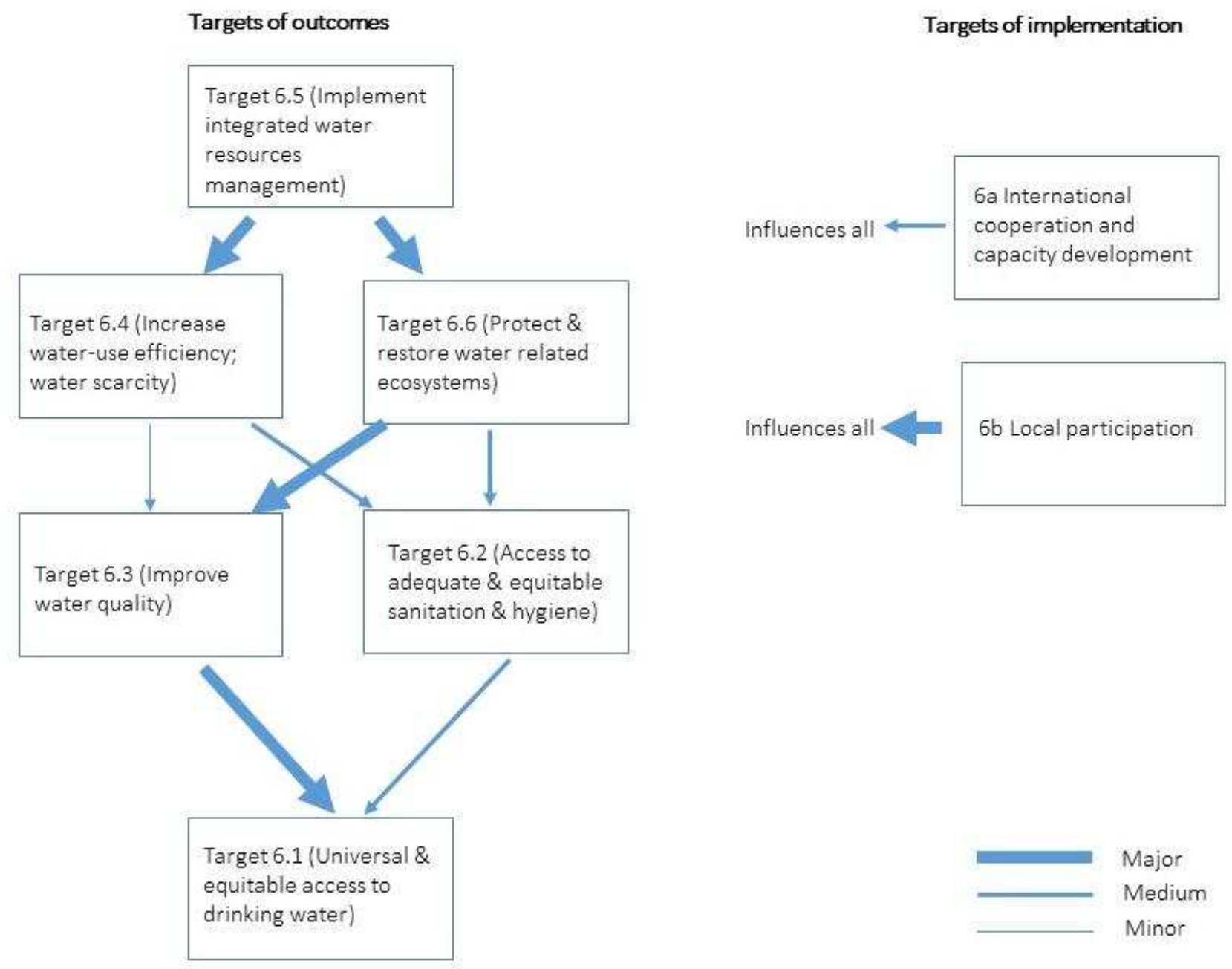

Figure 3: Relationship between targets of SDG 6 (water and sanitation)

\subsection{Limitations of the research}

It is noted that these findings were limited by the context within which the conversations were conducted in mid2016. This has shifted since the publication of further research and the responses from the Australian Government as they move towards submitting their Voluntary National Report to the UN.

A further limitation is the expertise and knowledge of the 11 researchers present in the workshop, as a different set of researchers may have raised different interpretations of the connections among the SDGs. The participant researchers acknowledged the potential for such outcomes during the workshops, but considered that this research 
was important to initiate the discussion in Australia regarding the interlinkages. Reader responses to these results are likely to expose how planning for SDG implementation is likely to default away from the complexity of deep interconnectedness due to competing connections that are established by disciplinary backgrounds and government agency portfolio boundaries. By presenting these findings, we have initiated a debate and offered one reading, with the intention to stimulate other responses. We do not claim this as definitive, but that engagement in interpretation is necessary and we invite other "readings" as a way of exploring debate around the commitment to the SDGs.

\section{Conclusions}

We concluded that the process of identifying the relationships between the SDGs at a 'goal' level was more difficult and generated less applicable results than conducting the same analysis an SDG 'target' level. This was in part due to the breadth of the goals, in comparison with the more specific targets. We also concluded that this exercise could be repeated at several levels to produce diagrams relevant to the implementation tasks at different levels, such as global (e.g. climate change issues), national (e.g. policy), and local scales (e.g. community participation).

Furthermore, we resolved that cyclical systems approaches may better enable additional influences to be identifiedas it could include positive and negative feedback loops.

The Departments of Foreign Affairs and Trade, and of Environment and Energy, were found to be relevant to six or more SDGs. However, a greater number of Australian Government agencies could contribute to achieving the SDGs to potentially deliver the greatest efficiency from investment and avoidance of negative outcomes from crossinfluences. Overall, no single agency can deliver the goals comprehensively, nor can one SDG be attained through the actions of a single agency. This finding justifies the subsequent decision by DFAT and DPMC to create to interdepartmental committee as Australia moves to prepare its Voluntary National Report and plan towards SDG achievement.

Identifying the interlinkages between the SDGs has value beyond the exercise itself for planning. It can enable consideration and debate regarding the SDG interlinkages in other international settings. Extending this debate invites other explorations, constructing other relationships and overlaying them on our structure to achieve the SDGs. The systems framework optimises the potential emergence of structures and synergies necessary to achieve the SDGs. This approach can be adapted for achievement by a range of agencies and at different scales to assist policy- and other decision-makers to enable the attainment of the UN sustainable development agenda by 2030.

\section{References}

ABS. 2018. 2030 Agenda on Sustainable Development, http://www.abs.gov.au/websitedbs/D3310114.nsf/Home/2030+Agenda+on+Sustainable+Development (accessed 19/3/18). Canberra: Australian Bureau of Statistics.

APH. 2016. Answers to Questions On Notice: Supplementary Budget Estimates 2016 - 2017, December 2. Canberra: Senate Finance and Public Administration Legislation Committee, Australian Parliament House.

APH. 2017. Terms of Reference: The United Nations Sustainable Development Goals, https://www.aph.gov.au/Parliamentary Business/Committees/Senate/Foreign Affairs Defence and Trade LSDGs/Terms of Reference (accessed 19/3/18). Canberra: Australian Parliament House.

Australian Govt. 2018. List of departments and agencies, https://www.australia.gov.au/aboutgovernment/departments-and-agencies/list-of-departments-and-agencies (accessed 19/3/18). Canberra: Australian Government.

AWA. 2017. United Nations Sustainable Development Goals: Discussion Paper, http://www.awa.asn.au/documents/Discussion Paper United Nations Sustainable Development Goals.pd $\mathrm{f}$ (accessed 14/7/17). Sydney: Australian Water Association.

Bartram, J. 2015. Water and Health: Sustainable Development Goals- Lecture to The University of the South Pacific, Port Vila, Vanuatu, 25 November. Chapel Hill NC: University of North Carolina.

Cain, J. 2001. Planning improvements in natural resources management: Guidelines for using Bayesian networks to support the planning and management of development programmes in the water sector and beyond. Oxon, UK: Centre for Ecology and Hydrology.

Cameron, C., P. Hunter, P. Jagals, and K. Pond. 2011. Valuing Water, Valuing Livelihoods: Guidance on Social Costbenefit Analysis of Drinking-water Interventions, with special reference to Small Community Water Supplies. Geneva.: International Water Association and World Health Organisation. 
Cumming, O., L. Watson, and A. Dangour. 2016. "Water, sanitation and hygiene: A missing link to food and nutrition security." In Routledge Handbook of Food and Nutrition Security, edited by B. Pritchard, R. Ortiz and M.

Shekar, 442-454. London and New York: Routledge.

DFAT. 2015. Global Development, http://dfat.gov.au/aid/topics/development-issues/global-developmentagenda/Pages/global-development-agenda.aspx (accessed 19/4/16). Canberra: Department of Foreign

Affairs and Trade, Australian Government.

DFAT. 2018. Voluntary National Review, http://dfat.gov.au/aid/topics/development-issues/2030agenda/Pages/voluntary-national-review.aspx\#responsibilities (accessed 19/3/18). Canberra: Department of Foreign Affairs and Trade.

Dovers, S., and K. Hussey. 2013. Environment and Sustainability: A Policy Handbook. 2nd ed. ed. Sydney: The Federation Press.

Düspohl, M., S. Frank, and P. Döll. 2012. "A Review of Bayesian Networks as a Participatory Modeling Approach in Support of Sustainable Environmental Management." Journal of Sustainable Development 5 (12):1-18.

Fischer, J., W. Steffen, K. Daniell, S. Garnett, R. Heinsohn, B. MacDonald, B. Newell, L. Robin, and A. Wade. 2007. "Mind the sustainability gap." Trends in Ecology \& Evolution 22 (12):621-624. doi: doi.org/10.1016/j.tree.2007.08.016.

Gallagher, L., J. Dalton, C. Brethaut, T. Allan, H. Bellfield, D. Crilly, K. Cross, D. Gyawali, D. Klein, S. Laine, X. LeFlaive, L. Li, A. Lipponen, N. Matthews, S. Orr, J. Pittock, C. Ringler, M. Smith, D. Tickner, U. von Schlippenbach, and F. Vuille. 2016. "The critical role of risk in setting directions for water, food and energy policy and research." Current Opinion in Environmental Sustainability 23:12-16.

Griggs, D. , M. Stafford-Smith, O. Gaffney, J. Rockström, M. Öhman, P. Shyamsundar, W. Steffen, G. Glaser, N. Kanie, and I. Noble. 2013. "Sustainable development goals for people and planet." Nature 495 (21 March):305-307.

Hall, N., E. Abal, S. Albert, S. Ali, D. Barrington, A. Dean, B. Head, P. Hill, K. Hussey, P. Jagals, G. Muriuki, M. Pascoe, S. Reid, R. Richards, J. Robinson, H. Ross, J. Torero Cullen, and J. Willis. 2016. The UN Sustainable Development Goals for water and sanitation: How should Australia respond within and beyond its borders? Brisbane: Global Change Institute, The University of Queensland.

Henriksen, H., and H. Barlebo. 2008. "Reflections on the use of Bayesian belief networks for adaptive management." Journal of Environmental Management 88:1025-1036.

Hovmand, P. 2014. Community-based system dynamics. New York Springer.

ICSU. 2017. A guide to SDG interactions: From science to implementation, https://www.icsu.org/cms/2017/05/SDGsGuide-to-Interactions.pdf (accessed 16/05/17). Paris: International Council for Science.

Juech, C., and E. Michelson. 2011. "Rethinking the Future of Sustainability: From silos to systemic resilience." Development 54 (2):199-201.

Karazhanova, A. 2015. Highlights of the UN-Water Regional Expert Water Regional Consultation on Water Security in the Asia-Pacific Region. Manila: United Nations Economic and Social Commission for the Asia Pacific.

Kuhnert, P., T. Martin, and S. Griffiths. 2010. "A guide to eliciting and using expert knowledge in Bayesian ecological models." Ecology Letters 13:900-914.

Le Blanc, D. 2015. Towards integration at last? The sustainable development goals as a network of targets: Working Paper No. 141. Geneva: United Nations Department of Economic and Social Affairs.

Loevinsohn, M., L. Mehta, K. Cuming, A. Nicol, O. Cumming, and J. H. J. Ensink. 2015. "The cost of a knowledge silo: a systematic re-review of water, sanitation and hygiene interventions." Health Policy and Planning 30 (5):660674. doi: 10.1093/heapol/czu039.

Maani, K., and R. Cavana. 2007. Systems Thinking, System Dynamics. Managing Change and Complexity. Auckland: Pearson Education.

Marlow, D. R., M. Moglia, S. Cook, and D. J. Beale. 2013. "Towards sustainable urban water management: a critical reassessment." Water Res 47 (20):7150-61. doi: 10.1016/j.watres.2013.07.046.

Mitchell, C., D. Cordell, and D. Fam. 2015. "Beginning at the end: The outcome spaces framework to guide purposive transdisciplinary research." Futures 65:86-96.

Nadkarni, S., and P. Shenoy. 2004. "A causal mapping approach to constructing Bayesian networks." Decision Support Systems 38 (2):259- 281.

Nikolova, A. , A. Karazhanova, N. Schneider, and K. Weinberger. 2017. Integrated Approaches for Sustainable Development Goals Planning: The Case of SDG 6 on Water and Sanitation, http://www.unescap.org/sites/default/files/publications/Integrated\%20Approaches\%20for\%20SDG\%20Plan ning 0.pdf (accessed 09/6/17). Bangkok: United Nations Economic and Social Commission for the Asia Pacific. 
Nilsson, M., D. Griggs, and M. Visbeck. 2016. "Map the interactions between Sustainable Development Goals." Nature 534 (16 June):320-322.

Office of PM. 2016. Remarks at High Level Water Panel, United Nations, September 21, http://www.pm.gov.au/media/2016-09-21/remarks-high-level-water-panel-united-nations (accessed 22/08/17). Canberra: Office of Prime Minister Malcolm Turnbull.

Prüss-Üstün, A., R. Bos, F. Gore, and J. Bartram. 2008a. Safer water, better health: costs, benefits and sustainability of interventions to protect and promote health. Geneva: World Health Organization.

Prüss-Üstün, A., R. Bos, F. Gore, and J. Bartram. 2008b. Safer water, better health: costs, benefits and sustainability of interventions to protect and promote health. Geneva: World Health Organization.

Richards, R. 2016. Bayesian network models: An Introduction. Brisbane: The University of Queensland.

Rogers, B.C., K. Hammer, L. Werbeloff, and C. Chesterfield. 2015. Shaping Perth as a Water Sensitive City: Outcomes of a participatory process to develop a vision and strategic transition framework. Melbourne: Australia: Cooperative Research Centre for Water Sensitive Cities

SCRGSP. 2016. Overcoming Indigenous Disadvantage: Key Indicators 2016 edited by Productivity Commission. Canberra.

Senge, P. 1990. The Fifth Discipline. New York: Doubleday/Currency.

Senge, P., and J. Sterman. 1992. "Systems thinking and organizational learning: Acting locally and thinking globally in the organization of the future." European Journal of Operational Research (59):137-150. doi: 10.1016/03772217(92)90011-W.

Singh, G., A. Cisneros-Montemayor, W. Swartz, W. Cheung, J.A. Guy, T. Kenny, C. McOwen, R. Asch, J. Laurens Geffert, C. Wabnitz, R. Sumail, Q. Hanich, and Y. Ota. 2017. "A rapid assessment of co-benefits and trade-offs among Sustainable Development Goals." Marine Policy In press, https://doi.org/10.1016/i.marpol.2017.05.030. doi:https://doi.org/10.1016/i.marpol.2017.05.030.

Spangenberg, J. 2016. "Hot Air or Comprehensive Progress? A Critical Assessment of the SDGs." Sustainable Development, DOI: 10.1002/sd.1657:1-11.

Sterman, J. 2000. Business Dynamics: Systems Thinking and Modeling for a Complex World. Boston: Irwin McGrawHill.

UN. 2015. Transforming our world: The 2030 agenda for sustainable development. New York: United Nations.

UN. 2016. Sustainable development knowledge platform: Participating states- Australia https://sustainabledevelopment.un.org/memberstates/australia (accessed 29/8/16). New York: United Nations.

UN. 2017. High Level Panel on Water webpage, https://sustainabledevelopment.un.org/HLPWater (accessed 14/7/17). New York: United Nations.

UN ESCAP. 2017. Integrated approaches for Sustainable Development Goals planning: The case of Goal 6 on water and sanitation. Bangkok: United Nations Economic and Social Commission of the Asia Pacific.

UN Women. 2016. SDG 6: Ensure availability and sustainable management of water and sanitation for all, http://www.unwomen.org/en/news/in-focus/women-and-the-sdgs/sdg-6-clean-water-sanitation (accessed 22/8/17). New York City: United Nations' Women.

UNESCAP. 2014. Pacific Consultation on Progress on the Millennium Development Goals and the Post-2015 Development Agenda. Bangkok: United Nations Economic and Social Commission for Asia and the Pacific.

Vensim. 2016. "Vensim Software, http://vensim.com/vensim-software/(accessed 12/12/16)." Ventana Systems.

Vladimirova, K., and D. Le Blanc. 2016. "Exploring Links Between Education and Sustainable Development Goals Through the Lens of UN Flagship Reports." Sustainable Development, DOI: 10.1002/sd.1626 24:254-271.

Vorosmarty, C. J., P. B. McIntyre, M. O. Gessner, D. Dudgeon, A. Prusevich, P. Green, S. Glidden, S. E. Bunn, C. A. Sullivan, C. R. Liermann, and P. M. Davies. 2010. "Global threats to human water security and river biodiversity." Nature 467 (7315):555-561. doi: Doi 10.1038/Nature09440.

Watson, R., J. Thwaites, D. Griggs, T. Kestin, and K. McGrath. 2014. Sustainable development goals and targets for Australia: An interim proposal. Melbourne: Sustainable Development Solutions Network and Monash Sustainability Institute.

WHO. 2014a. Investing in water and sanitation: increasing access, reducing inequalities. Geneva: World Health Organization.

WHO. 2014b. Preventing diarrhoea through better water, sanitation and hygiene: exposures and impacts in low- and middle-income countries. Geneva: World Health Organization. 
WHO, and UNICEF. 2014. A regional perspective based on new data from the WHO/UNICEF Joint Monitoring Programme for Water Supply and Sanitation: 2014 Update. Geneva: WHO/UNICEF Joint Monitoring Programme for Water Supply and Sanitation, World Health Organisation.

WHO, and UNICEF. 2016. Joint monitoring programme for water supply and sanitation. Geneva: World Health Organisation and United Nations Children's Fund.

WHO WPRO. 2016. Sanitation, drinking-water and health in Pacific island countries : 2015 update and future outlook. Manila: Regional Office for the Western Pacific, World Health Organisation.

Wilson, R. 2006. "Policy analysis as policy advice." In The Oxford Book of Public Policy, edited by M. Moran, M. Rein and R. Goodin. Oxford, UK: Oxford University Press.

WSAA. 2017. Global goals for local communities: Urban water advancing the UN Sustainable Development Goals. Melbourne: Water Services Association of Australia.

Zhang, Q., C. Prouty, J. Zimmerman, and J. Mihelcic. 2016. "More than Target 6.3: A Systems Approach to Rethinking Sustainable Development Goals in a Resource-Scarce World." Engineering 2:481-489. 